\title{
Low-Cost System for Managing of Tool's Storage
}

\author{
Vladimir Sojka ${ }^{1, *}$, Petr Lepsik ${ }^{1}$ \\ 1 Department of Design of Machine Elements and Mechanisms, Faculty of Mechanical Engineering,Technical University of Liberec, Liberec, Czech \\ Republic
}

\begin{abstract}
Companies with custom production often need to store a lot of unique tools. Amount of these tools is always increasing. That can lead to problems with storing of these tools. Storages are often overfull and unorganized. In those cases, it takes a lot of time to find specific tool, and it is an issue which generates many other wastes. Because software solutions for storage management which can resolve this problem are expensive, companies cannot afford to buy them. This problem is calling for some low-cost solutions to manage these storages. Solutions cheap and simple that every company can afford to implement. This low-cost solution could be a system of storage control, based on paper cards with simple database. This article shows how to implement the card system to unorganized storage and how can this system improve storage management, establish order and reduce waste in storage. This all is proven by a case study in glass making company at storage of wooden forms for parts made by glassblowing, that study is also included.
\end{abstract}

Keywords: storage management; card system; waste reduction

\section{Introduction}

In companies with custom production there are often technologies which need to have lots of unique tools. In many cases tools are stored for use in future. Acquiring new tools could cause problems in storage system. If there is poorly organized storage system, that can lead to wastes. First waste can be waiting, because long time for find a right tool could cause a manufacturing stop. Second waste is manipulation, tools are often stacked on piles, so if one needs to be taken others must be manipulated with too. Last issue of these storages is that sometimes employees cannot find a specific tool so they make a new one. That leads to doubled tools and if there are more tools in the storage, the storage is more and more unsystematic, and that leads to bigger and bigger wastes. Optimization of storages is often done only in form of new layout or in rearranging of tools [1-3].

This article is focused on reduction of wastes, caused by wrong storage of big amounts of unique tools in custom production, and implementation of low cost storage managing system. Article also includes a case study in storage of wooden forms for glassblowing.

\section{Experimental Section - Methods}

First step to do is categorization of all tools in storage. The Storage has to be "cleaned up", for example with method 5S (Sorting, Set in order, Shine, Standardize, Sustain) $[4,5]$, basically all objects which are not tools to store must be outside of the storage area, that also includes old and broken tools. It is important to know how many tools are in the storage, if there is not any list of them they must be counted manually. Tool's dimensions are needed for capacity calculation. Dimension analysis 
must also include anomalies like for example dimension difference after use or if tool replaced it can have different outside dimensions.

Tools can be also divided to some basic categories, some tools can be used for different activities or there can be different shapes of tools and so on. For these categories is usable to find out what the ideal way of storage is - if usual shelves are good enough or if there is some better opinion. Main result must be that every tool has its own position and every tool can be taken without moving other tools. Type and number of shelves is determined by dimensions of tools. It is good to look at increasing trend of tools per year and make capacity of storage big enough to be in this state for more than few months.
Next step is to make good layout of shelves and decide where which tool will be. Best solution is to make analysis by Pareto [6] or ABC analysis [7-9]. Most used tools should be put to the front area of storage to reduce the distance of walking. Shelves must be named and signed for better orientation (on the mark of the shelf can be also written the type of tools which are inside the shelf).

\subsection{Card system of storage management}

Card system is for better orientation in storage. Every tool has its own card, on the card is identification of the tool (name, number, etc.), type of the tool and location in storage. On the card can be also other information (for example dates of elimination or recovery of tool).

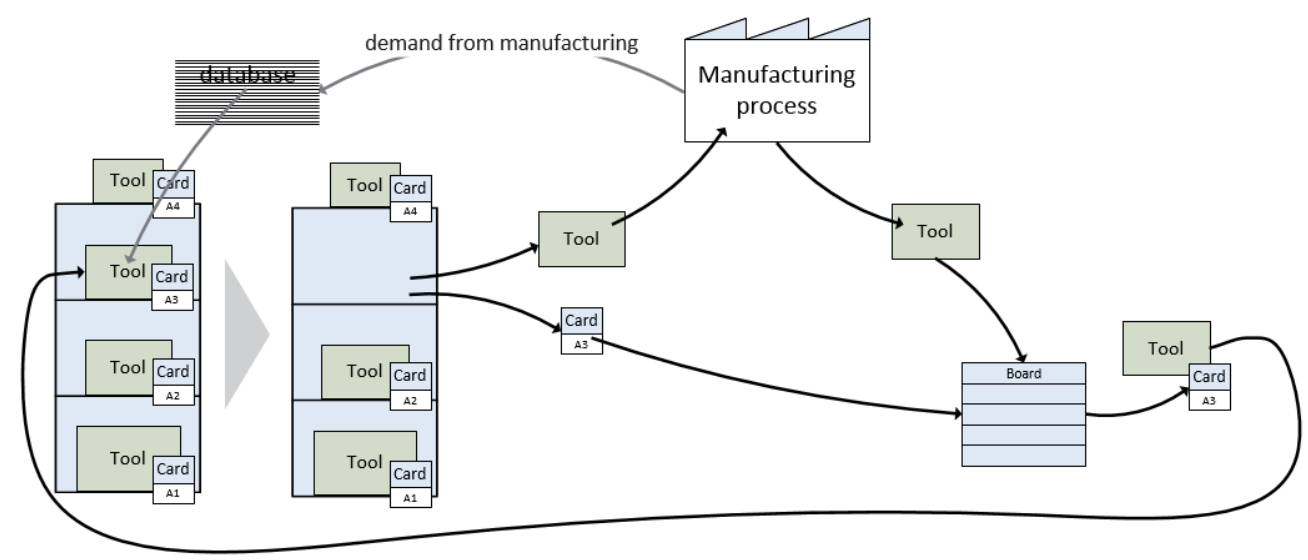

Fig. 1: Visualization of the Card system.

Card system is visualized on [Figure 1]. When a tool is inside of a shelf the card is in the shelf too. After taking the tool to production the card is placed on a board near to the entrance into the storage. When you look on the board you can see how many and which tools are in the manufacturing at the moment. When manufacturing is done and tools are returning to the storage, cards with location of each tool are recovered from the board and can be immediately used to put the tool into right place in storage without any searching.

In case that a tool is in manufacturing and a new tool is being assigned to a place, there is second type of card, this card is called "occupied", it is used for marking of empty place in a shelf while tool is located in manufacturing. It prevents from having two or more tools on one place.

\subsection{Database}

There is need for database of tools to the card system work better. Simple chart database where a list of all tools is enough. Database also including all basic information about the tool, its location in the storage and its state. The state of tool says where the tool is. It shows if is in manufacturing, or in storage, or if is broken and new one needs to be made.

When demand comes to a manager he can see in this database if the tool is ready for use or not. And he knows where exactly the tool is located. He can get the tool without searching. Only issue here is that every worker which can change the state of tool must also immediately change the state in this database. Otherwise information will not be correct.

\subsection{Case study}

This theory was proven on a case study in glass 
manufacturing company, which makes almost only custom production of glass and metals assemblies. This case is focused on storage of wooden forms for parts made by glassblowing.

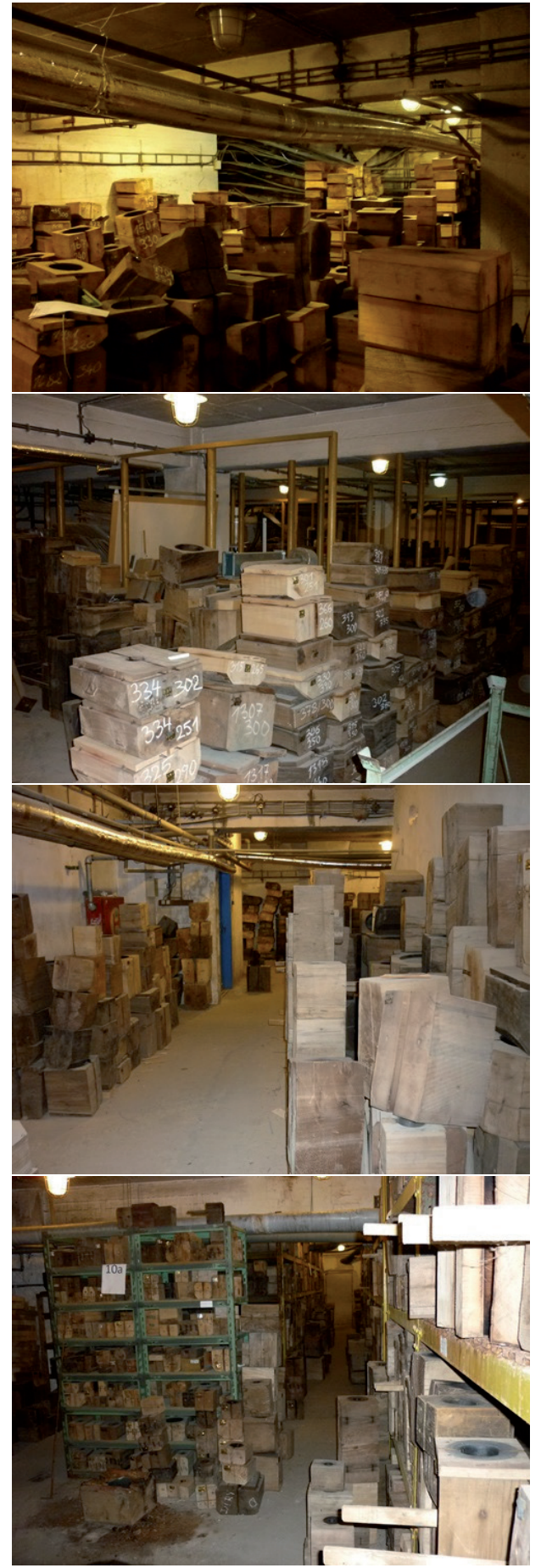

Fig. 2: Original state of storage.
As it is seen on [Figure 2] forms are stored on top of each other. Often there are forms stored on the floor. Whole storage area is in a basement and shelfs are without signs. That leads to possible wastes. As it was written above there is waste of several types like waiting till form is found, manipulation with others forms to get the demanded form. And production of forms which were not found, but they are in the storage. Big problem here was that only one person knows where which form could be. In a situation when this person was ill, other employees searched for specific wooden form more than one hour. Other issue was also a bad environment of storing. There was high humidity and it condensed on metal pipes. This water dripped on forms on several places. Forms were destroyed by water, mushrooms, and insects, rapidly faster than they could be destroyed in a dry storage. These destroyed forms were often still in storage until production needed them and it was found that these forms are broken as it is on [Fig. 3].

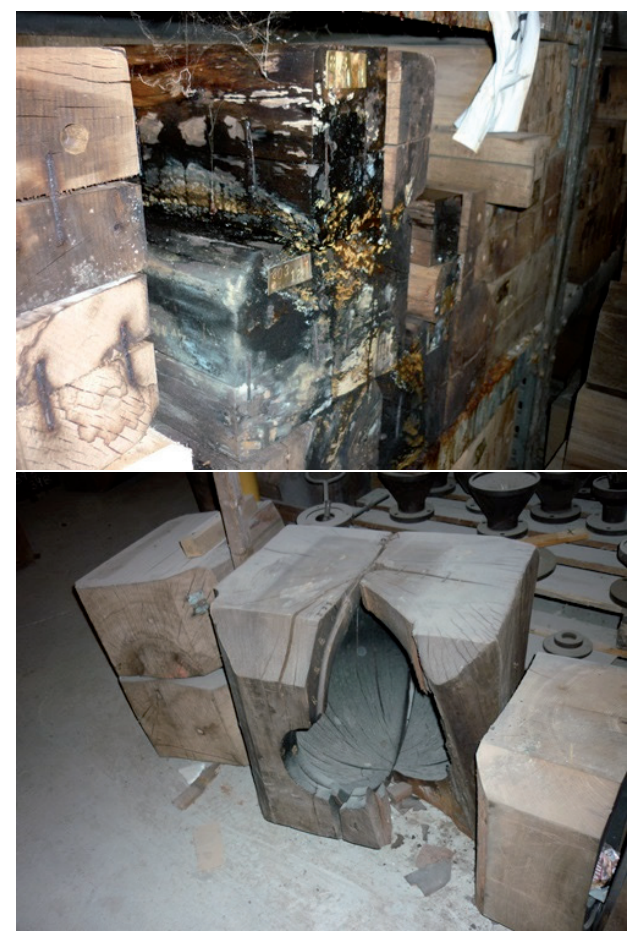

Fig. 3: Example of destroyed forms

After quick analysis of storage, a visualization of wooden forms lifecycle, for better knowledge of storage processes and production needs, was done. At first was all things which have nothing to 
Tab. 1: Add a descriptive label of the table here.

\begin{tabular}{|l|l|l|l|}
\hline Form category & Small (to $15 \mathrm{~cm})$ & Medium $(15-35 \mathrm{~cm})$ & Big $($ more than $35 \mathrm{~cm})$ \\
\hline Count & 1372 (approx. 40\%) & 1031 (approx. 30\%) & 1045 (approx. 30\%) \\
\hline
\end{tabular}

Tab. 2: Pareto and $A B C$ analysis results.

\begin{tabular}{|l|l|l|l|l|}
\hline Category & Cumulated percent & \multicolumn{1}{l}{ Number of orders } & Number of forms & \multicolumn{1}{l|}{ Number of forms (\%) } \\
\hline A & $0-34.9 \%$ & 501 & 69 & $11.3 \%$ \\
\hline B & $34.9-78.7 \%$ & 628 & 235 & $38.5 \%$ \\
\hline C & $78.7-100 \%$ & 306 & 306 & $50.2 \%$ \\
\hline
\end{tabular}

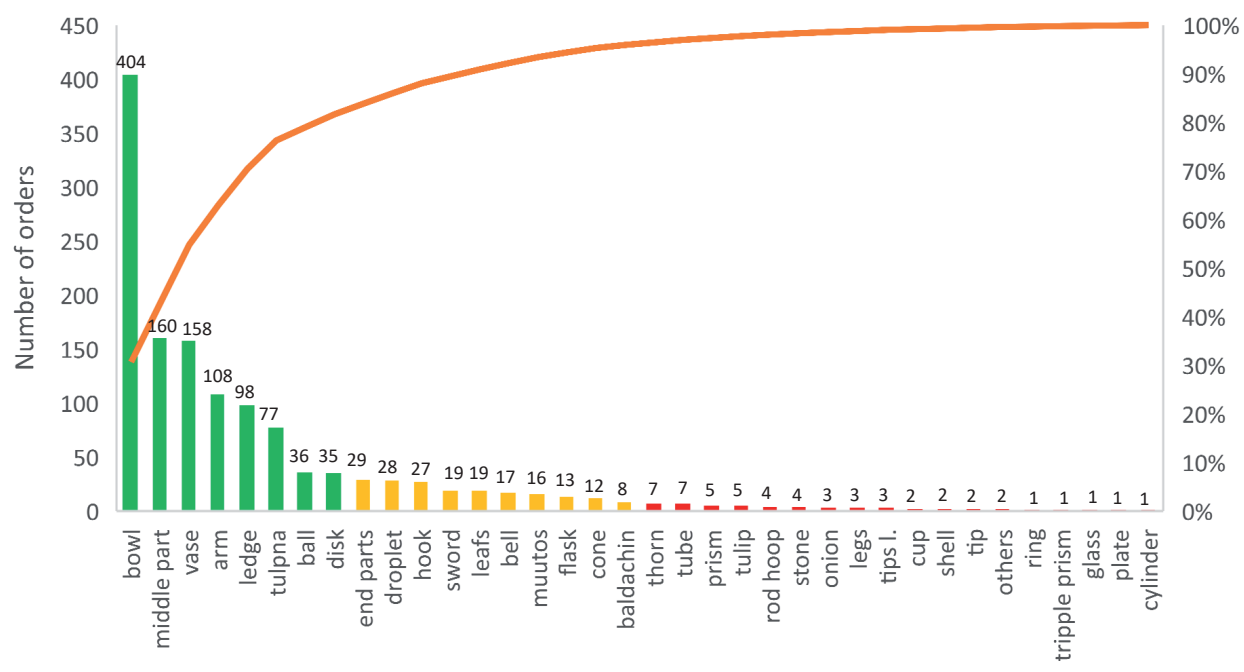

Fig. 4: Pareto and $A B C$ analysis for types of forms.

do in area of storage were eliminated. There was a lot of old materials, some broken forms and NOK products.

Because there was not any list of all forms in the storage, it had to be counted and measured manually. Results of counting and measuring were that there are approximately 3500 wooden forms in the storage. Dimensions of forms are from few centimetres to $75 \mathrm{~cm}$ in all three ways. All the forms were divided to categories by their height. Categories were: small forms with height to $15 \mathrm{~cm}$, medium forms with height from 15 to $35 \mathrm{~cm}$, and big forms which are higher than $35 \mathrm{~cm}$. That is seen in [Table 1]. There were also few unexpected forms which were for example thin but very high, only small amount of these type of forms was found. Storing of these forms had to be made individually.

Next step was analysis of data from information system. In the system there was not a data related to forms, there was only data for parts. Data was filtered from last two years. After filtering data for only glass parts made by blowing, Pareto and $A B C$ analysis was used to get a better overview which types or forms are most used. The main parameter of $A B C$ analysis is a number of orders for form. Table [Table 2] shows results of $A B C$ analysis of all forms in storage. Cumulated percentage for dividing forms into categories A, B and C were changed to 0-35\%, $35-80 \%$ and $80-100 \%$. That was done for better categorization into three groups. These groups ( $A$, $B$ and C) could be used for place order in storage. During the results of Pareto and $A B C$ analysis was decided, that storage will be categorized by type of parts which can be made by wooden form. Figure [Figure 4] shows results of $A B C$ analysis for types of forms.

Demanded length of shelves for every category of the forms was calculated for purchase of new shelves. To the width of each form was added 15\% of its width. It is because of outside dimensions can be different by approximately 5\% when the form is remade. The Next 10\% can be caused by 
wood swelling $[10,11]$ after wet form is returned to the shelf from manufacturing. To this length 2 more centimetres were added for manipulation space. Then all lengths of forms were summed. After summarization the needed length of shelves for each group of forms was known. By reviewing history, there is expected increase of approximately 200 new forms per year. So the length of shelfs was even more extended for future capacity.

Space for new shelves was made by destroying old shelves for glass melting pots which were unused. New floor was made and all pipes were insulated to prevent a condensation of humidity. After new shelves were installed, every form was putted to its place. All shelves were named and also marked. To every cell in shelf was given a location. In one cell can be more than one form [Figure 5].

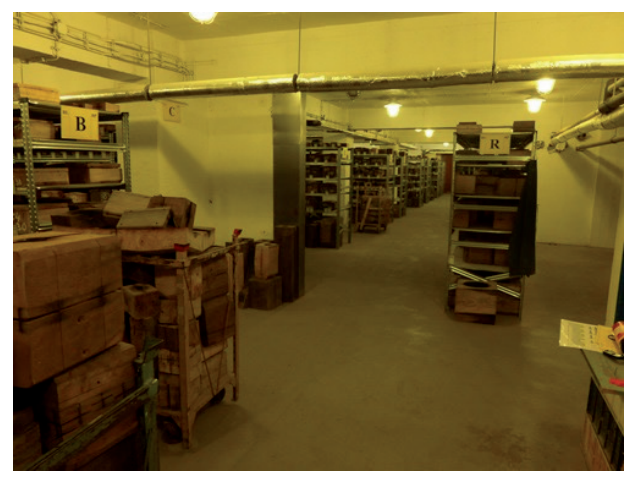

Fig. 5: Final state, after reorganization of storage.

After that the card system could be implemented. Cards were given to forms one by one, information about forms and location were written on cards manually. On the board near to an entrance to the storage map of storage with names of shelves was placed, for faster orientation in the storage. When every form got its place and card, database of all forms was made. State of form can be: in storage, in manufacturing, eliminated, in replacement, boiling.

When demand comes, the manager of manufacturing can find the state and location of the form in the database of forms. The form can be found only in several minutes and no doubled forms are made now.

\section{Results and Discussion}

As a result of implementation of the card system is well managed storage of tools [Figure 6]. This system can be very cheap and simple and also effective way to manage it. System itself reduces wastes like walking and searching for the specific tool. It pushes employees to have well organized and clean storage with no tools laying on each other. The biggest weakness of this system is the need of actual data in database, that could be problem with long term discipline of employees.

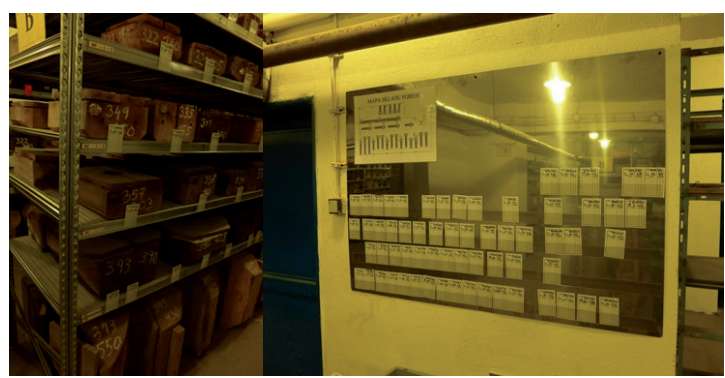

Fig. 6: Card system on shelfs and board after implementation.

Reduction rate of wastes is depending on every case where this system would be implemented. During implementation it is possible to reach other optimizations in storage like elimination of parts and materials which are not intended for this storage. Implementation of card system to storage is very cheap. Only costs are to print the cards, make board and card holders to shelves. Other costs are connected with renovation of storage area, not with the system itself.

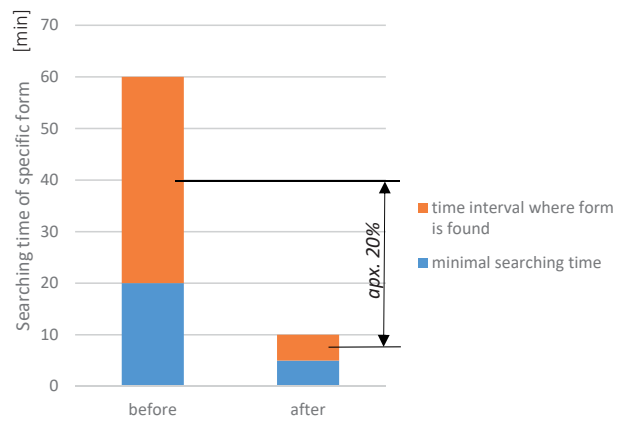

Fig. 7: Comparison of results with original state.

Functionality of card system was verified by case study in glass manufacturing company. Searching time after implementation had rapidly decreased. No doubled forms are in storage now. Overall time improvement was approximately from former 20-60 minutes to 5-10 minutes. Searching time was shortened by approximately $20 \%$ [Fig. 7]. Improvement by $20 \%$ is ordinary rate of 
improvement in Lean projects $[12,13]$. This means that Card system of storage managing works well.

\section{Conclusions}

The Card control system is universal low-cost solution for storages of tools (such as forms and other) in companies where custom manufacturing is the main part of production. This system allows to organize storage in a way that any tool can be found in very short time, but it is also very cheap to implement compared to solutions with software support. Rate of improvement is depending on a specific case, as results of case study shows it is possible to reach at least $20 \%$ reduction of searching time.

\section{Acknowledgments}

This publication was written at the Technical University of Liberec as part of the project "Innovation of the products, equipment and processes in engineering practice" with the support of the Specific University Research Grant, as provided by the Ministry of Education, Youth and Sports of the Czech Republic in the year 2019.

\section{References and Notes}

[1] Dharmapriya, U. S. S., Kulatunga, A. K. (2011). New Strategy for Warehouse Optimization - Lean warehousing. International Conference on Industrial Engineering and Operations Management, Kuala Lumpur, 513-519.

[2] Rouwenhorst, B., Reuter, B. (2000). Warehouse design and control: Framework and literature review. European Journal of Operational Research, volume 122, issue 3, 515-533.

[3] Van den Berg, J. P., Zijm, W. H. M. (1999). Models for warehouse management: Classification and examples, International Journal of Production Economics, volume 59, issues 1-3, 519-528.

[4] Michalska, J., Szewieczek, D. (2007). The 5S methodology as a tool for improving the organisation. Journal of Achievements in Materials and Manufacturing Engineering, volume 24, issue 2, 211-214.

[5] Agrahari, R. S., Dangle, P.A. (2015). Implementation of 5 S Methodology in the Small Scale Industry: a Case Study. International Journal of Advance Research and Innovation, volume 3 , issue 1, 130-137.

[6] Hochman, H., \& Rodgers, J. (1969). Pareto Optimal Redistribution. The American Economic Review, 59, 4, 542-557.

[7] Flores, B. E., Whybark, D. C. (1986). Multiple Criteria ABC Analysis, International Journal of Operations \& Production Management, volume 6, issue 3, 38-46.

[8] Flores, B. E., Whybark, D. C. (1987). Implementing multiple criteria ABC analysis. Journal of Operations Management, volume 7, 79-85.

[9] Chu, Ch. W., Liang, G. S. (2008), Controlling inventory by combining $A B C$ analysis and fuzzy classification. Computers \& Industrial Engineering, volume 55, issue 4, 841-851.

[10] Mantanis, G. I., Young,R. A. (1994). Swelling of wood Part I. Swelling in water. Wood Science and Technology, volume $28,119-134$

[11] Peck, E. C. (1957). How Wood Shrinks and Swells. Forest Products Journal, volume 7, number 7, 235-244

[12] Dhandapani, A., Potter, A. (2007). Applying lean thinking: a case study of an Indian steel plant. International Journal of Logistics Research and Applications, volume 7, issue 3, 239250.

[13] Miller, G., Pawloski, J. (2010). A casestudy of lean, sustainable manufacturing. Journal of Industrial Engineering and Management, volume 3, issue 1, 11-32. 